\title{
Por que ler Clássicos da comunicação: os teóricos de Peirce a Canclini
}

Roberta Brandalise

Jornalista formada pela Universidade Federal de Santa Maria (UFSM); mestre e doutora em Ciências da Comunicação formada pela Universidade de São Paulo (USP). Professora dos cursos de graduação e pós-graduação em Comunicação na Faculdade Cásper Líbero.

E-mail: robertabrandaliserb@gmail.com

Resumo: A resenha se propõe a apresentar como a leitura da obra Clássicos da comunicação: os teóricos de Peirce a Canclini, publicada em 2017 e organizada pelos professores Leonel Aguiar e Adriana Barsotti - com a contribuição de pesquisadores doutores que representam instituições de ensino de todas as regiões do Brasil -, dialoga com a contemporaneidade dos estudos de comunicação. A coletânea expõe como as teorias elaboradas por esses autores, além de tecerem a memória do campo, provocam o pensamento crítico e se fazem atuais junto a questionamentos sobre as próprias ideias e conceitos que foram transformados em referências clássicas do campo da Comunicação.

Palavras-chave: comunicação; teoria; história; referências clássicas.
Abstract: This review presents how the reading of the work Clássicos da comunicação: os teóricos de Peirce a Canclini [Classics of communication: the theorists from Peirce to Canclini], published in 2017 and organized by professors Leonel Aguiar and Adriana Barsotti - with the contribution of $\mathrm{PhD}$ researchers representing teaching institutions of every Brazilian region -, dialogues with the contemporaneity of communication studies. The collection exposes how the theories elaborated by these authors, besides building the memory of the field, evoke the critical thinking and make themselves current along with questions about the own ideas and concepts that have been transformed into classical references of the field of Communication.

Keywords: communication; theory; history; classical references.

Um clássico é um livro que nunca terminou de dizer aquilo que tinha para dizer. (Italo Calvino)

Clássicos da comunicação: os teóricos - de Peirce a Canclini ${ }^{1}$, organizado pelos professores Leonel Aguiar ${ }^{2}$ e Adriana Barsotti ${ }^{3}$, e publicado em 2017 pela parceria entre a Editora PUC-Rio e a Editora Vozes, é uma coletânea composta por 20 artigos escritos por 26 pesquisadores brasileiros sobre autores que foram transformados em referências teóricas clássicas no campo da comunicação.

1. AGUIAR, Leonel; BARSOTTI, Adriana (orgs.). Clássicos da comunicação: os teóricos - de Peirce a Canclini. Petrópolis: Vozes, 2017.

2. Leonel Aguiar é doutor em Comunicação (UFRJ), professor do Programa de Pós-Graduação em Comunicação da PUC-Rio e coordenador de graduação do Departamento de Comunicação Social da PUC-Rio.

3. Adriana Barsotti é doutoranda do Programa de Pós-Graduação em Comunicação da PUC-Rio, professora dos cursos de Jornalismo da ESPM-RJ e Ibmec. 
Bem ao estilo Italo Calvino ${ }^{4}$, alicerce dos próprios organizadores de Clássicos da comunicação, é preciso dizer, logo de início, que reler os clássicos implica descobertas. Ao colocá-los em diálogo com a realidade contemporânea, os articulistas nos remetem tanto à tessitura dos estudos de comunicação, desde o início do século XX, quanto a um pensar crítico sobre a conjuntura social e histórica que experimentamos na atualidade.

As ideias e conceitos que engendraram o campo nos provocam a interpelar a realidade e a analisar se, e como, as próprias reflexões teóricas que tomamos como clássicas ainda nos ajudam a elaborar perguntas sobre, explicar acerca de, articular com uma multiplicidade de questões, compreender, e mesmo intervir nos processos de comunicação na contemporaneidade.

Com a participação de articulistas que integram a heterogeneidade do campo da comunicação no Brasil, representam a diversidade regional do país e atuam como professores e pesquisadores de escolas de comunicação públicas e privadas, os organizadores Aguiar e Barsotti nos oferecem uma obra que pode contribuir com a formação de estudantes e professores, da graduação à pós-graduação, em Ciências da Comunicação.

Cada capítulo de Clássicos da comunicação leva o nome de um teórico relevante na formação do campo, recorrentemente citado em comunicação, e mesmo em outras áreas das Ciências Humanas. A estruturação do livro se dá pela ordem de nascimento dos autores e, em todos os vinte capítulos, apresentam-se elementos sobre a vida, a obra, alguns dos principais conceitos e ideias que enriqueceram a área de comunicação. Ao citar a bibliografia elaborada pelos teóricos há ênfase nas traduções para a língua portuguesa.

São eles alguns dos autores mais importantes da moderna tradição do campo da comunicação: Charles Sanders Peirce (1839-1914), Ferdinand de Saussure (1857-1913), Walter Benjamin (1892-1940), Roman Jakobson (1896-1982), Paul Lazarsfeld (1901-1976), Harold Lasswell (1902-1978), Theodor Adorno (1903-1969), Wilbur Schramm (1907-1987), Marshall McLuhan (1911-1980), Roland Barthes (1915-1980), Elisabeth Noelle-Neumann (1916-2010), Edgar Morin (1921-), Noam Chomsky (1928-), Jürgen Habermas (1939-), Guy Debord (1931-1994), Umberto Eco (1932-2016), Jesús Martín-Barbero (1937-), Eliseo Verón (1935-2014), Maxwell E. McCombs (1938-) e Néstor García Canclini (1939-).

A estrutura da coletânea representa uma estratégia que não direciona a leitura da obra para o engendramento do campo da comunicação e seus debates fundadores, deixando de chamar a atenção para a totalidade de suas regularidades e especificidades, aproximações e distanciamentos. De toda a forma, o desenvolvimento do livro a partir da ordem de nascimento dos autores supre uma lacuna editorial e é interessante para visualizarmos a multiplicidade de abordagens e problemáticas dos teóricos, mesmo quando contemporâneos entre si.

E a particularidade da contextualização histórica do pensamento desses

4. CALVINO, Italo. Por que ler os clássicos. Tradução de Nilson Moulin. São Paulo: Companhia das Letras, 1993. clássicos se faz perceber ao longo de cada capítulo, uma vez que o projeto editorial seguido pelos ensaístas contempla algumas especificidades, tais como formação, posição social e trajetória, que nos permitem entender a articulação 
do pensamento dos autores no meio acadêmico, considerando aspectos sociais, culturais, econômicos e políticos.

Sobre o clássico Charles Sanders Peirce (1839-1914), a ensaísta Lúcia Santaella ${ }^{5}$ lembra que o autor deixou 12 mil páginas publicadas em revistas científicas e 90 mil páginas de manuscritos. A articulista, que foi presidente da Charles S. Peirce Society, destaca o projeto Collected Papers, que envolve a publicação dos manuscritos conservados na biblioteca de Harvard, em vinte volumes, dos quais, até então, foram publicados apenas oito. Ao explanar sobre a teoria dos signos, as relações de sentido, a recepção e apropriação da obra, assim como a abstração dos conceitos, a articulista argumenta que a semiótica se constitui em uma teoria da comunicação e que a própria elaboração peirceana de semiose se desenvolve a partir do processo de comunicação. A especialista fundamenta, assim, a fortuna crítica de Peirce no campo da comunicação. Não chega a problematizar, entretanto, a ideia atribuída ao próprio teórico de que a "semiótica geral deveria funcionar como uma teoria fundacional, como um método geral da-e-para a investigação científica" ${ }^{6}$. A especialista se perfila com essa proposta ao afirmar: "Ora, se isso é verdadeiro para qualquer campo científico ou disciplina, é ainda mais verdadeiro para a comunicação como campo do conhecimento"7 , corroborando uma premissa que suscita discussões no campo científico por se aproximar de uma perspectiva dogmática.

Ferdinand de Saussure (1857-1913) ganhou o epíteto de pai da linguística, é o semiólogo que explicou as relações de sentido a partir de dicotomias, numa perspectiva estruturalista, como nos permite compreender a ensaísta Denise Lima ${ }^{8}$. Saussure propõe que para pensar o processo de produção de sentidos precisamos estudar o código linguístico como uma estrutura social, seus elementos e regras, assim como a atuação original do indivíduo a partir dessa estrutura; propõe que o signo implica significante e significado, explica a relação de sentido estabelecida com o signo como um processo que envolve a associação de sentido entre forma e conteúdo - formas diferentes podem produzir sentido semelhante, assim como uma mesma forma pode produzir sentidos diferentes; enfatiza a importância de se estudar o signo em abordagem sincrônica (a variação de sentido de um contexto ao outro no mesmo recorte temporal) e diacrônica (a variação de sentido ao longo da história); consagra a ideia clássica de denotação (sentido mais amplamente compartilhado, associado a um signo) e conotação (variações de sentido conforme contexto); e a rica ideia de que operacionalizamos um código em dois eixos, o sintagmático (quando juntamos elementos diferentes para produzir sentido) e o paradigmático (quando escolhemos entre elementos semelhantes para produzir sentido). A apropriação crítica da ensaísta enfatiza o fato de que o princípio da arbitrariedade ainda permanece incompreendido por muitos estudiosos que se debruçaram sobre a obra póstuma de Saussure, Curso de linguística geral. Já a discussão sobre os elementos deterministas nessa perspectiva, a ideia de que os atores sociais são pensados pelas estruturas e atuam em um cenário que, não necessariamente, pode ser transformado, poderia ser ampliada no capítulo.
5. Doutora em Teoria Literária pela Pontifícia Universidade Católica de São Paulo e professora do Programa de Pós-Graduação em Semiótica da mesma universidade.

6. SANTAELLA, Lúcia. Charles Sanders Peirce (1839-1914). In: AGUIAR, Leonel; BARSOTTI, Adriana (orgs.). Clássicos da comunicação: os teóricos - de Peirce a Canclini. Petrópolis: Vozes, 2017, p. 26.

7. Ibidem, p. 26.

8. Doutora em Letras pela UFPB e pesquisadora da Universidade Federal de Campina Grande. 
9. Doutora em Filosofia pela USP e professora do Programa de Pós-Graduação em Estudos Culturais Contemporâneos da Universidade Fumec.

10. ARENDT, Hannah. Homens em tempos sombrios. Tradução de Denise Bottmann. São Paulo: Companhia das Letras, 1987.

11. Doutor em Comunicação pela UnB e professor do Departamento de Comunicação Social da Universidade Estadual do Centro-Oeste do Paraná.

12. Doutor em Ciências da Informação Medias pela Université Paris II/Panthéon-Assas e professor do Programa de Pós-Graduação em Comunicação e Cultura Contemporânea da UFBA.
Walter Benjamin (1892-1940) foi um dos mais perspicazes intérpretes da Modernidade, como sublinha a articulista Vanessa Salles ${ }^{9}$, o mais importante crítico de sua época, como disse Hannah Arendt ${ }^{10}$. O ensaísta alemão testemunha o desenvolvimento dos meios de comunicação e a apropriação pelo Terceiro Reich. Identifica a efemeridade e a obsolescência que caracterizam a vida do ser humano moderno, considerando as transformações da vida urbana na metrópole e a figura do flâneur, a arquitetura, a moda, a publicidade, a fotografia, o cinema, a prostituta, a criança, o estudante, entre tantos objetos de análise que vão da linguagem à filosofia, aos processos e meios de comunicação. Benjamin desenvolve a primeira teoria materialista da arte, discute a reprodutibilidade técnica, a aura, o valor de exposição, a transformação da própria ideia sobre o que é arte, considerando que não se pode negar a materialidade histórica e o desenvolvimento tecnológico, atentando para as implicações disso na circulação dos bens culturais, e considerando a possibilidade de democratização do conhecimento mesmo na predominância da lógica do capital.

Roman Jakobson (1896-1982) forneceu elementos para a elaboração de modelos de comunicação que explicassem a sociedade de massas, especialmente em seu diálogo com a Teoria da Informação, de Claude Shannon e Warren Weaver. Em perspectiva interdisciplinar, e partindo da linguística, por considerar um padrão estrutural para todos os outros sistemas de signo, o teórico estabelece a comunicação como troca, tal como enfatiza o ensaísta Silnei Scharten Soares $^{11}$. No modelo jakobsoniano de comunicação, a linguagem é central e a comunicação é o estudo da troca em três níveis, o antropológico ou cultural, o econômico e o semiótico. Jakobson se destaca ao criar o diagrama sobre o ato comunicativo que, de acordo com o clássico, ocorre com os seguintes fatores: remetente, mensagem, destinatário, contato, código e contexto. O teórico formalista russo, que influenciou inclusive o concretismo no Brasil, ainda é responsável pela elaboração do conceito de fonema, pela tessitura conceitual das funções da linguagem e a ênfase na análise linguística a partir se uma perspectiva estrutural do código. Com suas ideias e conceitos, Jakobson impactou mais diretamente a Teoria Literária e a Semiótica. Na teoria da comunicação, sua influência se fez perceber de forma mais direta nos modelos explicativos dos processos de comunicação, nos quais a linearidade e a transmissão predominam como chaves de leitura para pesquisas de efeitos sobre as audiências.

Paul Lazarsfeld (1901-1976) foi um dos pioneiros ao realizar pesquisas de comunicação no campo científico. O ensaísta Giovandro Marcus Ferreira ${ }^{12}$ enfatiza que, na iminência da Segunda Guerra, no advento do Rockefeller Seminar, os "pais da comunicação" se preocupavam em responder como os Estados Unidos poderiam utilizar os meios de comunicação a seu favor, na formação da opinião pública por exemplo, em caso de guerra mundial. Nesse contexto, Lazarsfeld foi um protagonista que se destacou desenvolvendo estudos que analisavam a influência dos meios de comunicação no eleitorado americano, discutindo a extensão do poder da mídia na sociedade, ao considerar em seus estudos a influência dos contatos pessoais, dos grupos de pertença, do reforço e 
da figura do líder de opinião. Junto de Robert Merton, Lazarsfeld preocupou-se com a substituição, no gosto popular, de algo que entendia como uma cultura autêntica por uma cultura-padrão criada e divulgada pela mídia; identificou o reforço de normas sociais como uma das funções da mídia na sociedade; conferir ou garantir status como outra função. Em sua obra, destaca-se ainda a clássica tessitura teórica da ideia de disfunção narcotizante, o efeito viciante de distração e dessensibilização das audiências. Os estudos de Lazarsfeld também voltaram-se para a análise da ideia de que o efeito da mensagem depende do uso que o indivíduo faz dela e da satisfação das necessidades do receptor, o que, de acordo com o articulista, implica em uma noção mais elaborada do receptor que, tal como podemos compreender, é visto como passivo com resistências, ou como "ativo", embora não "autônomo" nem "simétrico" em seu papel no processo de comunicação. Entre outros elementos de destaque na obra do teórico, o ensaísta aponta a influência de Lazarsfeld nos estudos de folkcomunicação, na América Latina, e, em especial no Brasil, a partir dos trabalhos de Luiz Beltrão.

Harold Lasswell (1902-1978) é a primeira referência teórica clássica dos estudos de comunicação a ser abordada no ensino sobre as teorias que fundamentam as pesquisas na área. O teórico foi um dos maiores clássicos da tradição americana de mass communication research e um dos fundadores do campo da comunicação nos Estados Unidos, tal como enfatiza a ensaísta Rafiza Varão ${ }^{13}$. O autor é responsável por ampliar o modelo aristotélico, no qual a comunicação é apresentada como um processo que envolve emissor, mensagem e receptor. Lasswell propõe que, para estudarmos esse processo, é preciso perguntar quem; diz o quê; por qual canal; para quem; e com quais efeitos. O teórico destacou-se pela compreensão de que os estudos sobre política precisam refletir sobre o papel da mídia e interessou-se pelo potencial da comunicação, especialmente da propaganda, na criação ou na transformação de atitudes e opiniões. Identificou como funções da mídia na sociedade a articulação das partes com o todo, a vigilância sobre o meio social e a transmissão de herança social. A ensaísta destaca que, partindo da Ciência Política, o teórico se fez central na história das teorias da comunicação, mas é efetivamente pouco lido na atualidade e bastante abordado de forma reducionista ou caricatural. A articulista propõe que, ao ser retomado, este clássico pode oferecer pistas para estabelecermos diálogo entre as tradicionais abordagens sobre comunicação e a sua configuração na conjuntura contemporânea.

Theodor Adorno (1903-1969) é o teórico clássico que, junto de Max Horkheimer, engendra a Escola de Frankfurt, o conceito de indústria cultural e acaba por estabelecer o que tomamos como o primeiro embate teórico do campo da comunicação, em relação à perspectiva funcionalista norte-americana, representada por autores como Lasswell e Lazarsfeld. Os quatro ensaístas ${ }^{14}$, Yuri Gushiken, Silvia Ramos Bezerra, Celso Francisco Gayoso e Joelton Nascimento, foram os responsáveis por redigir o capítulo sobre essa referência, que não é stricto sensu um teórico da comunicação, mas suas elaborações conceituais e a
13. Doutora em Comunicação pela UnB e professora dos cursos de Jornalismo e de Comunicação Social/Publicidade da Universidade Católica de Brasília.

14. Yuri Gushiken, doutor em Comunicação e Cultura pela UFRJ e professor do Programa de Pós-Graduação em Cultura Contemporânea da UFMT; Silvia Ramos Bezerra, doutora em Ciências da Comunicação pela USP e servidora da Prefeitura Municipal de Cuiabá; Celso Francisco Gayoso, doutor em Comunicação e Cultura pela UFRJ e professor da Universidade Federal do Sul da Bahia, e Joelton Nascimento, doutor em Sociologia pela Unicamp e professor da Universidade Federal do Mato Grosso. 
15. SCHRAMM, Wilbur (org.). Panorama da comunicação coletiva. Rio de Janeiro: Fundo de Cultura, 1964, p.14.

16. Doutora em Comunicação pela UFRGS e professora do Programa de Pós-Graduação em Ciências da Linguagem da Universidade do Sul de Santa Catarina.

17. Doutora em Ciências Sociais pela Pontifícia Università Gregoriana e professora do Programa de Pós-Graduação da Universidade Federal do Mato Grosso do Sul. articulação de suas ideias foram apropriadas como relevantes para a teoria da comunicação fundadora do campo. Os ensaístas sinalizam a contribuição das reflexões do teórico acerca da transformação da cultura em mercadoria, a ideia de que o consumidor não é rei, de que nos massificamos pelo consumo das mesmas mercadorias padronizadas, de que os meios de produção em comunicação atuam criando mercadorias entranhadas pela ideologia da classe dominante, que, quando consumidas, levam à internalização dessa visão de mundo e nos mantém em estado de conformismo social. Todas questões a serem revisitadas na contemporaneidade, com as devidas críticas. Considerando que não existe cultura superior ou inferior, e que a disputa de sentidos se dá na circulação, envolvendo um receptor que se apropria de forma complexa e heterogênea do que a indústria cultural tem a ofertar.

Wilbur Schramm (1907-1987) foi, em boa medida, responsável pela proposta de uma perspectiva de comunicação como área de conhecimento. Contribuindo para a institucionalização dos estudos de comunicação nos Estados Unidos e no exterior, articulando contatos entre centros de pesquisa, estabelecendo ações técnicas e administrativas. Nesse sentido, destaca-se sua influência na América Latina, a partir de estudos que relacionam a indústria cultural e o desenvolvimento social, especialmente, com a criação do Centro Internacional de Estudios Superiores de Periodismo para América Latina (Ciespal), pela Unesco, em 1959. Discutiu o percurso da comunicação interpessoal à comunicação de massa, estabelecendo que a comunicação é um processo social e que "os sinais têm apenas o significado que a experiência do indivíduo lhe permite interpretar"15. Introduzindo as ideias de comunicação circular, feedback e campo de experiência, tal como destaca a ensaísta Heloisa Juncklaus Preis Moraes $^{16}$, que termina por pontuar a relevância de revisitar de forma crítica esse clássico para pensar a desigualdade, em especial na América Latina, em tempos de profunda midiatização da vida social e a persistente centralidade acerca da ideia de nação.

Marshall McLuhan (1911-1980) estabeleceu conceitos e ideias partindo da premissa da não neutralidade das tecnologias, chamando a atenção para como os meios de comunicação, em especial, atuam como extensões do homem e para a ideia de que o meio é a mensagem. O mcluhanismo aponta ainda para a mudança na percepção do tempo e do espaço, para a transformação da sensibilidade e a reorganização da vida social. De acordo com a articulista Márcia Gomes Marques ${ }^{17}$, se o meio configura sentido e atua como extensão que amplia ou atrofia a ação humana, o otimismo que parece se manifestar em suas ideias parece não se sustentar de todo. Sobre a ideia de aldeia global, por exemplo, elaborada pelo teórico canadense, identifica-se o pioneirismo de suas reflexões acerca da simultaneidade, instantaneidade e as implicações para o mundo do trabalho, da educação e do entretenimento, de outro lado, o alerta sobre elementos deterministas e integrados em sua perspectiva é pontuado no artigo.

Roland Barthes (1915-1980) olha para o mundo e para si mesmo. Este teórico estudou texto e imagem em revistas, jornais e propagandas, imergiu no 
prazer do texto e teorizou sobre a mensagem fotográfica, chamando atenção para como a fotografia se constitui de forma paradoxal - é natural e cultural ao mesmo tempo, denota e conota -, e, ainda, destacou o paradoxo ético implicado na ação de fotografar. O ensaísta Frederico de Mello Brandão Tavares ${ }^{18}$ destaca que, em jornalismo, Barthes elaborou uma clássica discussão sobre fait divers. Ao lado de Ferdinand de Saussure - que muito influenciou o seu trabalho - é considerado um dos fundadores da Semiologia, mas, pode ser considerado um pós-estruturalista, muitas de suas reflexões valorizam os conceitos de sujeito e história. Considerou que as ideologias, por vezes, são absorvidas despercebidamente porque elas entranham o próprio código linguístico e este seria um dos motivos pelos quais os meios de comunicação têm potencial persuasivo.

Elisabeth Noelle-Neumann (1916-2010) foi uma pesquisadora do campo da comunicação que conquistou espaço entre os clássicos com a o conceito de espiral do silêncio. De acordo com a ensaísta Danila Cal ${ }^{19}$, Noelle-Neumann constrói as bases de sua teoria a partir do conceito de opinião pública, da teoria da percepção social, da discussão sobre controle social, da natureza social do homem, da pesquisa eleitoral e dos efeitos dos media. De acordo com a teórica, os conceitos de opinião pública, sanção e punição estão interligados, assim, ela argumenta que, para o indivíduo, não se isolar pode ser mais importante do que o próprio julgamento no processo de formação da opinião. É desta forma que, conforme o pensamento clássico da autora, a espiral do silêncio se estabelece e a mídia ganha centralidade nesse processo. A teoria pode contribuir para explicar alguns processos de silenciamento e elementos implicados nos processos de formação da opinião pública, tomando a mídia como articuladora central, numa abordagem que, tal como sublinha a ensaísta, parece se assemelhar de forma pioneira aos então futuros estudos de efeitos de enquadramento. As críticas a essa elaboração teórica, entretanto, também foram expostas no capítulo, especialmente, com respeito à ideia de passividade e fragilidade do indivíduo diante da pressão da opinião pública.

Edgar Morin (1921-) identifica na cultura de massa o próprio espírito do tempo do século XX, entende que a cultura de massa configura a sociedade contemporânea e que é preciso estudá-la para compreender os princípios que fundamentam essa época, e mesmo o século XXI, tal como registra a ensaísta Iluska Coutinho ${ }^{20}$ sobre parte das articulações teóricas que o transformaram em um clássico. Morin não associa a indústria cultural ao capitalismo, restritamente, ele demonstra que tanto no regime econômico americano quanto no soviético há características da cultura de massa e que, portanto, a cultura de massa é engendrada como parte da mentalidade do século XX. Na atualidade, o teórico se destaca pela elaboração da Teoria da Complexidade que pode ser mobilizada na comunicação, adotando o que ele chama de postura de ciência com consciência, enfatizando a circulação de diferentes saberes e a inserção das competências disciplinares no mundo da vida. A articulista destaca o artigo de 2003, "A comunicação pelo meio (teoria complexa da comunicação)", uma elaboração dialógica entre Morin e o tradutor brasileiro, o professor Juremir
18. Doutor em Ciências da Comunicação pela Unisinos e professor do Programa de Pós-Graduação em Comunicação e Temporalidades da Universidade Federal de Ouro Preto.

19. Doutora em Comunicação Social e Sociabilidade Contemporânea pela UFMG e professora do Programa de Pós-Graduação em Comunicação, Linguagens e Cultura da Universidade da Amazônia.

20. Doutora em Comunicação Social pela Umesp e professora do Programa de Pós-Graduação em Comunicação da UFJF. 
Machado. Nesse texto, que se propõe a localizar como a comunicação se estabelece na obra do teórico francês, Morin revela que considera mais importante estudar a cultura de massa que se desenvolve a partir da comunicação. Ou seja, como ele mesmo certifica, sempre se interessou por analisar objetos de interface da comunicação com outras áreas do conhecimento.

Noam Chomsky (1928-), de acordo com a ensaísta Célia Maria Ladeira Mota $^{21}$, entende que é parte do papel da intelectualidade analisar as ações dos governos, denunciar inverdades, identificar intenções. Sem perder de vista essa responsabilidade, além das elaborações teóricas sobre a gramática gerativa e suas contribuições para os estudos de linguística, Chomsky dedicou-se a realizar a análise crítica de mídia. Ele se transformou em uma voz dissonante em seu país, por estudar a influência dos meios de comunicação de massa na vida política e econômica dos Estados Unidos, especialmente, atentando para como ocorre a construção de consenso social alinhado com as diretrizes do poder. De acordo com a articulista, o teórico trabalha ainda com a teoria dos filtros na produção da notícia e, assim, demonstra como se dá a manipulação ideológica e o controle político do público, considerando a infraestrutura econômica das empresas de comunicação e suas implicações na cobertura noticiosa.

Jürgen Habermas (1939-), em Mudanças Estruturais da Esfera Pública, de 1962, estabelece que a opinião pública burguesa é influenciada pela mídia (positivamente ou negativamente) e que, de qualquer modo, a mídia é fundamental para a participação crítica dos cidadãos nas democracias modernas, tal como destacam os ensaístas Adilson Vaz Cabral Filho e Eula Dantas Taveira

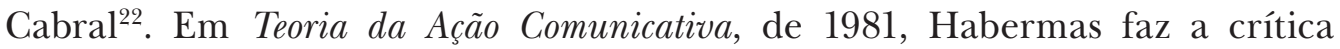
da razão funcionalista e recoloca o papel emancipatório da razão. A partir do conceito de agir comunicativo, o teórico que representa a segunda geração da Escola de Frankfurt busca superar o pessimismo dos frankfurtianos fundadores da Teoria Crítica, Horkheimer e Adorno. Entretanto, ao analisar o seu legado, que implica a reflexão sobre o papel do comunicador como

21. Doutora em Comunicação Social pela UnB e professora do Programa de Pós-Graduação em Comunicação da Universidade de Brasília.

22. Adilson Vaz Cabral Filho, doutor em Comunicação Social pela Umesp e professor dos Programas de Pós-Graduação em Mídia e Cotidiano e em Política Social da UFF; Eula Dantas Taveira Cabral, doutora em Comunicação Social pela Umesp e pesquisadora do Instituto Brasileiro de Informação em Ciência e Tecnologia. mediador social que, em alguma medida, pode ser relevante para garantir condições igualitárias de comunicação, os ensaístas problematizam pouco a proposta de Habermas. O teórico, ao sublinhar o que seria uma comunidade ideal de comunicação, em uma perspectiva utópica, a fim de retomar o papel emancipatório da razão pelo agir comunicativo, propõe uma perspectiva que o reservatório teórico do campo da comunicação já demonstrou não se sustentar, a de que pelo debate e diálogo poderíamos chegar ao consenso nos processos de comunicação.

Guy Debord (1931-1994) é o teórico que denuncia que vivemos na sociedade do espetáculo, caracterizada por um conjunto de relações sociais mediadas pela troca mútua de imagens. De acordo com Debord, todas as coisas foram transformadas em imagem, a forma mais desenvolvida da mercadoria no capitalismo, um sistema no qual a aparência passou a ser privilegiada. Adorno e Horkheimer demonstraram como a cultura foi transformada em mercadoria, e 
Debord demonstrou como a mercadoria foi transformada em cultura no hipercapitalismo. Sua obra é de crítica contundente e, como sinalizam as ensaístas Anita Leandro e Isabel Castro ${ }^{23}$, mais do que uma teoria da comunicação, o trabalho dele representa uma forma radical de atividade política.

Umberto Eco (1932-2016), intelectual profícuo, irônico, polêmico, pop, best-seller - é a partir desse registro que a ensaísta Gabriela Machado Ramos de Almeida ${ }^{24}$ destaca as elaborações do teórico acerca da arte, da ideia clássica de obra aberta, entre outros elementos conceituais que Eco tece ao analisar a cultura de massa e as narrativas populares e, ainda, o seu aporte à semiótica. Para Eco, compreender que a cultura de massa está por toda a parte não elimina a necessidade da crítica, e estudar seus produtos e textos pode gerar explicações sobre a própria realidade. A contribuição de Eco como teórico clássico do campo da comunicação se engendra no imaginário de gerações de estudantes, especialmente a partir do texto Apocalípticos e integrados, de1964, em que o autor sintetiza os argumentos do primeiro embate teórico do campo da comunicação, representado pelo debate entre funcionalistas norte-americanos e frankfurtianos.

Jesús Martín-Barbero (1937-) é um intelectual latino-americano que propõe o deslocamento do eixo de estudos dos processos comunicacionais para a cultura, dos meios às mediações, considerando as relações entre comunicação, cultura e hegemonia. O teórico problematiza a ênfase dos estudos de comunicação nos meios enquanto tecnologias, ou enquanto emissores poderosos como as indústrias da cultura e os governos, e explica que são as mediações culturais que intermedeiam o próprio processo de comunicação que, em boa medida, configuram o processo de produção de sentidos, de forma heterogênea e complexa, a partir de um receptor ativo, que utiliza e se apropria das mídias de acordo com seu contexto. O ensaísta Marcos Paulo da Silva ${ }^{25}$ assinala a relevância das mediações culturais nos processos de resistência aos sentidos hegemônicos, e a pertinência de um olhar latino-americano sobre o campo da comunicação, considerando a materialidade do processo histórico e o engendramento teórico deste clássico. Martín-Barbero incorpora a leitura de Karl Marx pelo debate proporcionado por Antônio Gramsci, rompe com o positivismo tecnologicista e com o etnocentrismo culturalista, se aproxima de Stuart Hall e estabelece diálogos, apropriações e debates interessantes, trabalhando conceitos de Pierre Bourdieu, Walter Benjamin, Michel de Certeau, Raymond Williams, Jürgen Habermas, Néstor García Canclini e Paulo Freire.

Eliseo Verón (1935-2014) elaborou a teoria da semiose social, ao estudar os discursos e o poder da imprensa latino-americana. Claude Lévi-Strauss, Roland Barthes e Umberto Eco foram algumas de suas referências mais próximas, mas a formação de Verón se evidencia como plural: estudou Charles S. Peirce, Jacques Lacan, Julien Greimas, Pierre Bourdieu, Michel Foucault, Alain Touraine, entre outros pesquisadores de diversas vertentes teóricas, tal como assinala a articulista Maria Cristina Gobbi ${ }^{26}$. Verón transformou-se em um clássico, referenciado de forma recorrente na atualidade, em razão do conceito de circulação discursiva
23. Anita Leandro, doutora em Estudos Cinematográficos e Audiovisuais pela Université Paris III/ Sorbonne Nouvelle, e professora do Programa de Pós-Graduação em Comunicação e Cultura da UFRJ; Isabel Castro, doutoranda do Programa Pós-Graduação em Comunicação e Cultura da UFRJ.

24. Doutora em Comunicação e Informação pela UFRGS e professora do Curso de Comunicação Social da Universidade Luterana do Brasil.

25. Doutor em Comunicação Social pela Umesp e professor do Programa de Pós-Graduação em Comunicação Social da UFMT.

26. Doutora em Comunicação Social pela Umesp e professora do Programa de Pós-Graduação em Comunicação e em Mídia e Tecnologia da Universidade Estadual Paulista. 
27. Doutora em Comunicação e Cultura Contemporânea pela UFBA e professora do Programa de Pós-Graduação em Comunicação e Temporalidades da Universidade Federal de Outro Preto.

28. Maria das Graças Pinto Coelho, doutora em Educação pela UFRN e professora dos Programas de Pós-Graduação em Estudos de Mídia e em Educação, da UFRN; Sebastião Faustino, doutor em Educação pela UFRN e professor do Departamento de Comunicação Social da UFRN.

29. BORGES, Jorge Luis. O idioma analítico de John Wilkins. In:

Outras inquisições: 1952.

Tradução de Davi Arrigucci Júnior. São Paulo: Companhia das Letras, 2007, pp. 121-126. e a análise da circulação dos discursos entre produção e recepção. Além disso, suas ideias se fizeram relevantes no debate do campo da comunicação acerca dos processos de midiatização da vida social.

Maxwell E. McCombs (1938-) estabelece o paradigma do agendamento, da clássica teoria da agenda-setting ao novo modelo de agenda-setting em rede. A articulista Jan Alyne Barbosa Prado ${ }^{27}$ estabelece a elaboração teórica que faz de McCombs um clássico. Junto de Donald Shaw, ele identificou que as pautas expostas na mídia tornam-se tópicos abordados nas relações sociais e culturais cotidianas. A teoria do agendamento envolve ainda a noção de que os meios de comunicação não definem como vamos nos posicionar sobre algo, mas pautam a agenda pública de discussões. Além disso, um meio de comunicação pode pautar o outro, e um produto midiático (de qualquer gênero ou formato, não restritamente jornalístico como fertilmente se discute) pode agendar as discussões que se dão em outro. A ensaísta aprofunda a discussão sobre a agenda-setting mostrando seu impacto sobre a tradição de pesquisas em media-effects, discorrendo sobre as várias fases de desenvolvimento dessa teoria, até a contemporaneidade. E, ainda, destaca que a base epistemológica da teoria do agendamento é a pesquisa estatística de base quantitativa e que, por isso, no Brasil - que não tem tradição de pesquisa quantitativa em comunicação - as apropriações e referências a esse clássico são limitadas.

Néstor García Canclini (1939-) é um dos intelectuais latino-americanos mais relevantes na contemporaneidade. Os ensaístas Maria das Graças Pinto Coelho e Sebastião Faustino situam esse clássico da comunicação delineando suas contribuições no debate acerca das relações entre as culturas locais e os processos implicados na globalização. Sobre as tensões entre homogeneização cultural e heterogeneização cultural, Canclini critica sistematicamente o eurocentrismo e propõe pensar a América Latina a partir do hibridismo cultural. Nesse contexto de mundialização da cultura e profunda midiatização da sociedade, se destacam suas reflexões acerca da diversidade de apropriações e usos implicados no consumo cultural, a participação do consumo na dinâmica das identidades culturais e, especialmente, a politização do consumo e a complexidade de suas relações com a cidadania.

Os clássicos que compõem a obra são aqueles teóricos que persistem na construção social do conhecimento científico em comunicação, e, de fato, a jornada de leitura nos apresentou inesquecíveis luminares. Entretanto, como os próprios organizadores identificaram e anteciparam, recorrendo a Jorge Luis Borges $^{29}$, toda a classificação é arbitrária e pode nos deixar com a impressão de que há "faltas" de outros inesquecíveis.

Portanto, mesmo sabendo que não há como dar conta desse enigma, ficamos a perscrutar o que significam algumas ausências, tais como os franceses Michel Foucault e Pierre Bourdieu, e suas reflexões acerca das relações de poder que estão dentro e fora do discurso, e as ideias de embate e disputa, que caracterizam os processos de comunicação; ou Stuart Hall e a tradição dos Estudos Culturais Britânicos; e mesmo Claude Elwood Shannon e Warren 
Weaver, criadores do, geralmente considerado clássico, modelo matemático da comunicação, entre outros.

Longe de demandar que a obra dê conta dessas inquietações, mas o não aprofundamento acerca dessas escolhas nos deixa a refletir sobre como as ausências, essas ou outras, geram implicações na leitura da própria configuração do campo e podem oferecer pistas sobre como estamos nos identificando, distinguindo ou transformando.

Sobre as transformações no campo da comunicação, é válido ainda registrar nota para futuras reflexões pertinentes ao espírito do tempo de nossa época, uma conjuntura na qual se faz relevante, por exemplo, observar a diversidade na produção intelectual em questão: dos 20 teóricos clássicos estudados na obra, três são latino-americanos e uma mulher; dos 26 articulistas brasileiros convidados para produzir os ensaios que configuram a obra, 10 são homens e 16 são mulheres.

Chegamos ao fim dessa leitura com felizes descobertas sobre teóricos clássicos que continuam nos instigando. Ao longo de cada página de Clássicos da comunicação: os teóricos - de Peirce a Canclini, revisitamos suas contribuições para a área da comunicação, por meio artigos ou ensaios com características didáticas e preocupados em situar tensões e críticas no reservatório teórico do campo acerca desses mesmos baluartes.

\section{REFERÊNCIAS BIBLIOGRÁFICAS}

AGUIAR, Leonel; BARSOTTI, Adriana (orgs.). Clássicos da comunicação: os teóricos - de Peirce a Canclini. Petrópolis: Vozes, 2017.

ARENDT, Hannah. Homens em tempos sombrios. Tradução de Denise Bottmann. São Paulo: Companhia das Letras, 1987.

BORGES, Jorge Luis. O idioma analítico de John Wilkins. In: Outras inquisições: 1952. Tradução de Davi Arrigucci Júnior. São Paulo: Companhia das Letras, 2007, pp. 121-126.

CALVINO, Italo. Por que ler os clássicos. Tradução de Nilson Moulin. São Paulo: Companhia das Letras, 1993.

SANTAELlA, Lúcia. Charles Sanders Peirce (1839-1914). In: AGUIAR, Leonel; BARSOTTI, Adriana (orgs.). Clássicos da comunicação: os teóricos de Peirce a Canclini. Petrópolis: Vozes, 2017. p. 26.

SCHRAMM, Wilbur (org.). Panorama da comunicação coletiva. Rio de Janeiro: Fundo de Cultura, 1964. 